\title{
Co-Ni Alloy Superlattice Electrodeposited Using a Rectangular Pulse Current over a Megahertz Frequency Range
}

\author{
M. Saitou \\ University of the Ryukyus, Department of Mechanical Systems Engineering, 1 Senbaru Nishihara-cho \\ Okinawa, 903-0213, Japan. \\ E-mail: saitou@tec.u-ryukyu.ac.jp
}

doi: $10.20964 / 2019.03 .81$

Received: 7 December 2018 / Accepted: 7 January 2019 / Published: 7 February 2019

$\mathrm{Co}-\mathrm{Ni}$ alloy superlattices with a periodic composition modulation of $\mathrm{Co}$ were electrodeposited on a $\mathrm{Cu}$ plate using 0.3 and $0.35 \mathrm{MHz}$ rectangular pulse currents. The energy dispersive X-ray spectroscopy analysis demonstrated that the Co content in the Co-Ni atomic layers electrodeposited at $0.3 \mathrm{MHz}$ was approximately two times higher than that at $0.35 \mathrm{MHz}$. The $\mathrm{Co}-\mathrm{Ni}$ alloy superlattices were comprised of unit lattices with high and low Co content atomic layers. The X-ray diffraction analysis demonstrated that the Co-Ni alloy superlattices had face-centered cubic crystal structures, and one Bragg diffraction peak from the Co-Ni alloy superlattice was observed in the small-angle X-ray scattering region. The lattice constants of the unit lattices were shown to be controlled by the number of $\mathrm{Co}-\mathrm{Ni}$ atomic layers with either high or low Co contents.

Keywords: Co-Ni alloy; Superlattice; Composition modulation: Small-angle X-ray scattering, Lattice constant

\section{$\underline{\text { FULL TEXT }}$}

(C) 2019 The Authors. Published by ESG (www.electrochemsci.org). This article is an open access article distributed under the terms and conditions of the Creative Commons Attribution license (http://creativecommons.org/licenses/by/4.0/). 